\title{
Integrated Modelling Approach for Climate Change Adaptation: The Case of Surf Life Saving Australia
}

\author{
$\underline{\text { O. Sahin }}^{\text {a,c }}$, R. Richards ${ }^{b, c}$ and M. Sano ${ }^{b, c}$ \\ ${ }^{a}$ Griffith School of Engineering, Griffith University, Queensland \\ ${ }^{b}$ Griffith Centre for Coastal Management, Griffith University, Queensland \\ ${ }^{c}$ Griffith Climate Change Response Program, Griffith University, Queensland \\ Email: o.sahin@griffith.edu.au
}

\begin{abstract}
Surf Life Saving Australia (SLSA) is Australia's main water safety and rescue authority whose assets and operations include 310 local surf lifesaving clubs and about 150,000 trained volunteers. Rising sea level and increased extreme events frequency pose serious threats to SLSA's assets and facilities. Therefore, this research aims to explore adaptation pathways and strengthen the capacity of SLSA to tackle these threats.

However, adaptation to climate change is very complex and encompasses a range of constraints such as reliable data, information, time and uncertainty which make quantification quite difficult. To overcome these challenges, the research team has utilised an array of techniques into a cohesive approach including participatory workshops, MIC-MAC and System Dynamics (SD). Through stakeholder engagement (workshops) and structural analysis (MIC-MAC), key variables were identified and an influence dependence chart (causal relationship) was created. Then, using an SD approach, first a conceptual model was built to understand potential values of SLSAs services given sea level rise (SLR) controls, adaption options, and feedbacks within and between the climate change and SLSA operations. The SD model consists of three interactive sub-models: a) Climate change; b) SLSA Operation; and c) Community.

The climate change sub-model, under a range of SLR scenarios, simulates changes in storm events frequencies which are vital to SLSA's operation and assets. Therefore, adaptation investment on all forms of accessibility would reduce the impact of extreme storm events on a club's operation. A community submodel is used to understand the impacts of changing climate, specifically resulting extreme events, on community located around clubs.
\end{abstract}

Keywords: $\quad$ Surf life saving Australia, Integrated modelling, Climate change adaptation, System dynamics 


\section{INTRODUCTION}

The Surf Lifesavers, with a long history and tradition of more than 100 years, have a unique role in Australia's culture: to save lives and prevent injuries for people who visit Australia's beaches. For instance, in 2010 Surf Lifesavers rescued approximately 12,000 people and avoided approximately 600 drowning deaths across Australia thanks to the volunteer patrol hours delivered, valued at approximately AU $\$ 165$ Million. The total value of Surf Life Saving across Australia is approximately AU\$3,412 Million in avoided injuries, permanent incapacitations and deaths (PWC, 2011).

Surf Life Saving Australia (SLSA) has assets and facilities exposed to extreme conditions due to climate variability and change, and these are located in close proximity to the coastal zone. These assets and facilities, including 310 separately incorporated local surf lifesaving clubs (SLSCs), are at the frontline of the impacts of climate change and are, therefore, exposed to extreme storms, sea level rise and other climate change impacts. The challenges posed by climate change are significant as $63 \%$ of SLSA's 310 clubs are located within zones of potential instability, and therefore, the SLSA has to act on climate change issues (Elrick et al., 2011).

Identifying climate change adaptation options, and understanding the adaptive capacity to implement these are critical for organisations or institutions involved in the adaptation process. Recent years, sophisticated research has been published, such as: the adaptation process of environmental management regimes (Young, 2010), complex regions such as the New York metropolitan area (Rosenzweig et al., 2011), water management (Huntjens et al., 2012; Sahin et al., 2013b; Siems et al., 2013), and coastal management (Tobey et al., 2010; Sahin, 2013; Sahin et al., 2013a). Accounting for climate change trends is a relatively new consideration for most non-government organizations and the private sector, however, research is being carried out to understand, conceptualise, and respond to its impacts (Berkhout et al., 2006; Winn et al., 2011). In this sense Surf Life Saving Australia has been proactive by producing a comprehensive study on the impact of climate change on its services (Elrick et al., 2011).

In this context, this paper, as part of the Adapt Between Flags project aimed to explore adaptation pathways and strengthen the capacity of SLSA to tackle these threats (Sanò et al., 2013), describes the system modelling process used to understand system behaviour and test adaptation options by using a range of systems techniques.

\section{APPROACH}

It is not easy to assess the effects of various adaptation options using linear models of cause and effect. Such linear modelling assumes that if the cause is doubled the effects would be doubled accordingly. This thinking can be highly misleading in complex social-ecological systems where causation is driven by accumulation and feedback (Newell et al., 2011). Evidently, most environmental systems are defined by feedbacks, interdependencies, and chaotic and discontinuous non-linear relations of their elements (Kauffman, 1993; Patten and Jørgensen, 1995). In the same way, SLSA and SLSCs located along the coastlines are also characterised by their multiple interdependent components that together produce multiple economic, environmental, ecological and social impacts.

Faced with bounded rationality resulting from a limited knowledge about future conditions, inadequate capabilities to handle uncertainties, and short decision timeframes, adaptation decisions are usually made during or after crisis caused by extreme events, and often to not deliver desired outcomes. In order to make an optimal decision under uncertainty, all known factors and probabilities affecting the SLSCS and its customers must be taken into account. Generally, these factors are interdependent and interlinked, forming a complex feedback relationships network. Therefore, decision makers should utilize a suitable method to solve this complex probabilistic and dynamic decision problem. To do so, incorporating all key factors into modelling requires a dynamic approach that would provide much needed knowledge (or understanding) of future behaviour of all key factors in the system.

Computer models of complex systems are frequently used to support decisions concerning environmental problems. To successfully use these models, it is not enough for groups of researchers to build and run the models. It requires not only inter-disciplinary consensus, but also participation of stakeholders. Stakeholder participation in decision-making around models of environmental systems is crucial to determining the successes and failures of adaptation management. Dietz (2003) suggests that the environmental decisions must be grounded in both science, and fair and competent public consultation process. According to Dietz, criteria for a good collective decision should include; human and environmental well-being, competence about facts and values, fairness in the process and outcome, reliance on human strengths rather than 
weaknesses, the opportunity to learn and efficiency. Timing of stakeholders' participation in decision-making process is essential in creating flexible adaptation alternatives. The sooner they (the stakeholders) become involved in the decision / modelling process, the greater the opportunity to achieve a successful adaptation.

We employed a participatory approach in identifying key variables and evaluating adaptation alternatives. Participatory modelling is the process of incorporating stakeholders, often including the public, and decision makers into an otherwise purely analytic modelling process to support decisions involving complex natural resources questions (Voinov and Gaddis, 2008).

Throughout the modelling process, continuous involvement of stakeholders in the model building, scenario development, data collection and identification of adaptation alternatives stages significantly improves the value of the resulting model in terms of its usefulness to decision makers, its educational potential for the public, and its credibility within the community (Korfmacher, 2001; Johnson, 2009). Thus, the model development flowed through a multi stage process, including: 1) Stakeholder identification and engagement; 2) Problem scoping and model conceptualisation (first round of workshops); 3) Structural Analysis; 4) SD model development; and 5) Model testing and calibration (Second round of workshops). These steps are briefly described below with particular emphasis on SDM development:

\subsection{Stakeholder identification and engagement, stakeholder analysis}

The aim of this phase was to identify and engage relevant stakeholders in each case study area. A basic snowballing sampling technique called Hydra (Sano et al., 2010) was employed to build stakeholder networks and select stakeholders for the workshops. The process started by defining the object of the potential impacts i.e. issues or elements describing Assets, Operations and Community (AOC). A second step was to identify climatic and non-climatic drivers, which may affect these issues/elements of the system. These issues/elements were then connected to other drivers that may impact the AOC system. The final step was to identify adaptive responses to these impacts including coastal engineering works, relocation of facilities, training and education of volunteers, etc.

\subsection{Problem scoping and model conceptualisation (first round of workshops).}

The first round of workshops were organised for problem scoping and system conceptualization, using systems thinking techniques to build a model of the system with the help of stakeholders. Action is pointless without a goal. At this stage, through scenario building, a goal and research direction was established.

\subsection{Structural Analysis.}

The first round of data analysis involved a structural analysis of the conceptual model produced by the stakeholders. Structural analysis is a methodology designed to link up ideas, which allows stakeholders / researchers to describe the system using a matrix linking all its constitutive elements. By studying these relations, this methodology enables analysts to underline the variables that are essential to the system's evolution. It has the advantage of stimulating reflection within the group, and leading it to think about certain aspects, which are sometimes counterintuitive. It applies to the qualitative study of extremely different systems. The system under study comes in the form of a group of interrelated elements (variables/factors). In this instance, structural analysis was enriched using the MICMAC approach (MICMAC is the French acronym for Matrix of Crossed Impact Multiplications Applied to a Classification) to identify key variables and their influences on each other (Godet, 2006). These elements' interrelations web constitutes the key of its dynamics and remains quite permanent (Arcade et al., 1999).

\subsection{System Dynamics Model (SDM) development}

The SDM, using the platform Vensim ${ }^{\circledR}$ DSS (Ventana Systems, 2012), was built by identifying key variables, establishing causal relationships between these variables and finally parameterising these relationships. Although there are many commercial programs available, Vensim has some advantages for presentation and analysis such as causal tracing, sensitivity analysis and optimization that make Vensim a good choice for complex modelling. In building the SDM, a participatory modelling approach was employed. Participatory model development can focus on portraying system structure, while model simulations reveal system behaviour, which is less intuitive and often the source of confusion (Vennix et al., 1996; Van den Belt et al., 2004; Langsdale et al., 2007). To build the model and raise the shared level of understanding, we have worked with assumptions regarding parameters and responses drawn from a range of experts from academia, private consulting firms and government water agencies, in order to produce a logical simulation model. 
The SDM is composed of three main components: a) Climate change; b) SLA Operation; and c) Community sub-modules. There is a strong interdependency between these components of the SDM. Simulation involves modelling joint variations in key parameters, (e.g. estimating) the effect of decreasing one or more key factors and simultaneously increasing one or more other key factors. That is, the SDM enables a time-based exploration of various combined scenarios and alternatives (i.e. a new road, increased adaptive capacity, and population growth), and provides better visualization of how SLSA operation and assets would be affected in over time, thereby revealing any feedbacks that might cause unexpected changes in other parts of the system.

\subsection{Model testing and calibration}

The validation of any model, in the sense of establishing robust results across variations of assumptions, is important to examine whether the proposed model is realistic and useful to the users; it should answer the question: "Was the model successful at addressing its intended purpose?" That is, the proposed model matches the real-world (Sojda, 2007) as seen by informed observers. The Project Team discussed the outcomes of the analyses with the stakeholders, and explored the stakeholders' feedback in improving the model structure at the second round of workshops. Thus, this model was validated using 2 methods: 1) parameter validation; and 2) overall model validation through stakeholder engagement. The parameter validation was used to obtain the values for the parameters by using randomly generated data based on historical data such as extreme event frequency, beach closure, and population growth. Stakeholder consultation was used to assess the validity of the major components of the model through seeking agreement about the following aspects: input data validity; modelling logic (i.e. parameter relationships); and ensuring the model output adequately reflects the real situation.

\section{DEVELOPMENT OF SUBMODELS}

\subsection{Climate Change sub-model}

The climate change sub-model (Figure 1) comprised both sea level rise (SLR) and changes in annual storm surge frequencies as they are vital to SLSCs operation and assets. Simulation of the climate change sub-model model under a range of SLR scenarios facilitated changes in storm events frequencies. The climate change sub-model use differential and difference equations to represent the interconnections in a system. The state variable, Sea Level, changes over time depending on the flow rate, Increase. The mathematical representation of the Stocks and Flows diagram (Figure 1) are:

$$
\begin{aligned}
& S L=\int(I) \mathrm{dt}+[0] \\
& I=\text { Rrate }
\end{aligned}
$$

Where $S L$ represents the sea level at time $t$, while the $I(\mathrm{t}-\mathrm{dt})$ shows the rate of increase at time (t-dt), [0] denotes initial sea level. Rrate represents annual changes in sea level.

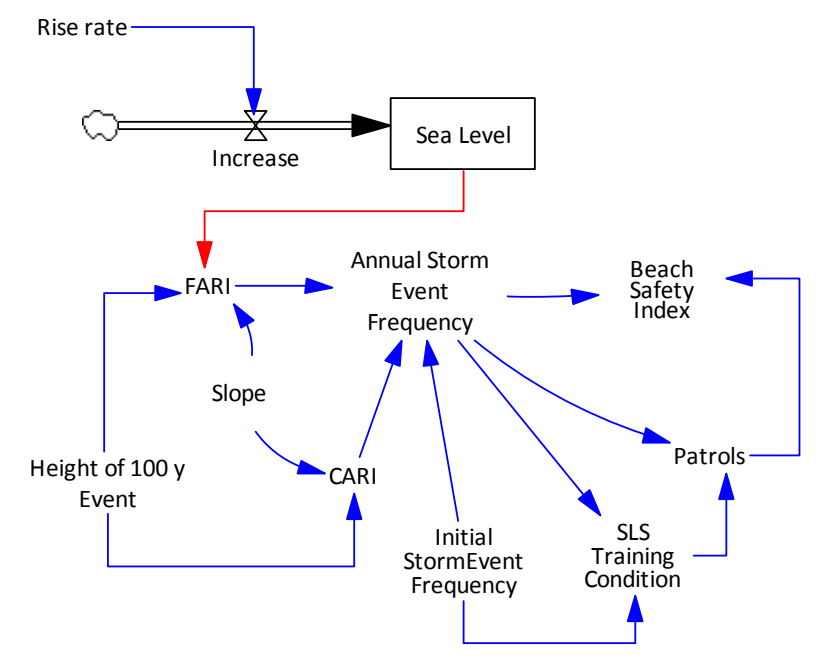

Figure 1. Climate change sub-model simulating sea level rise and resulting changes in a storm event frequencies.

Annual storm event frequency $(A S E F)$ is the function of initial storm event frequency, current $(C A R I)$ and future annual recurrence interval $(F A R I)$, and was calculated using the following Equation (3):

$$
A S E F=I S E F *(C A R I / F A R I)
$$

Where $C A R I$ represents the average, or expected, value of the periods between exceedance of a given storm event over a given duration at a location. FARI indicates the average return period of a storm event changing over time depending on the sea level. Harper et al. (2000) projected that the highest storm tide levels (relative to the Australian Height Datum) within the Moreton Bay region (where one of the case study SLSCs is located) for 50, 100, 500 and 1000 year storm events are $2.3 \mathrm{~m}, 2.5 \mathrm{~m}, 3.2 \mathrm{~m}$ and $3.5 \mathrm{~m}$, respectively. By fitting trend lines to these projections and to Sea Level data computed using Equation 1 and 2, CARI and FARI conditions could be estimated using equations 4 and 5 respectively. 
Sahin et al., Integrated Modelling Approach for Climate Change Adaptation: The Case of SLSA

$$
\begin{aligned}
& C A R I=0.4094 \ln \mathrm{X}+0.6594 \\
& F A R I=0.4094 \ln \mathrm{X}+(0.6594+\text { Sea Level })
\end{aligned}
$$

Where X represents the height of a given storm event. For this research, 1-in-100 year storm surge event was used for calculations. $A S E F$ was identified by one of the key variables affecting the SLSCs, and used a number of variables to simulate the impacts on clubs' operation and community.

\subsection{Operation sub-model}

The operation sub-model consists of 35 variables, five of which are state variables (Figure 2).

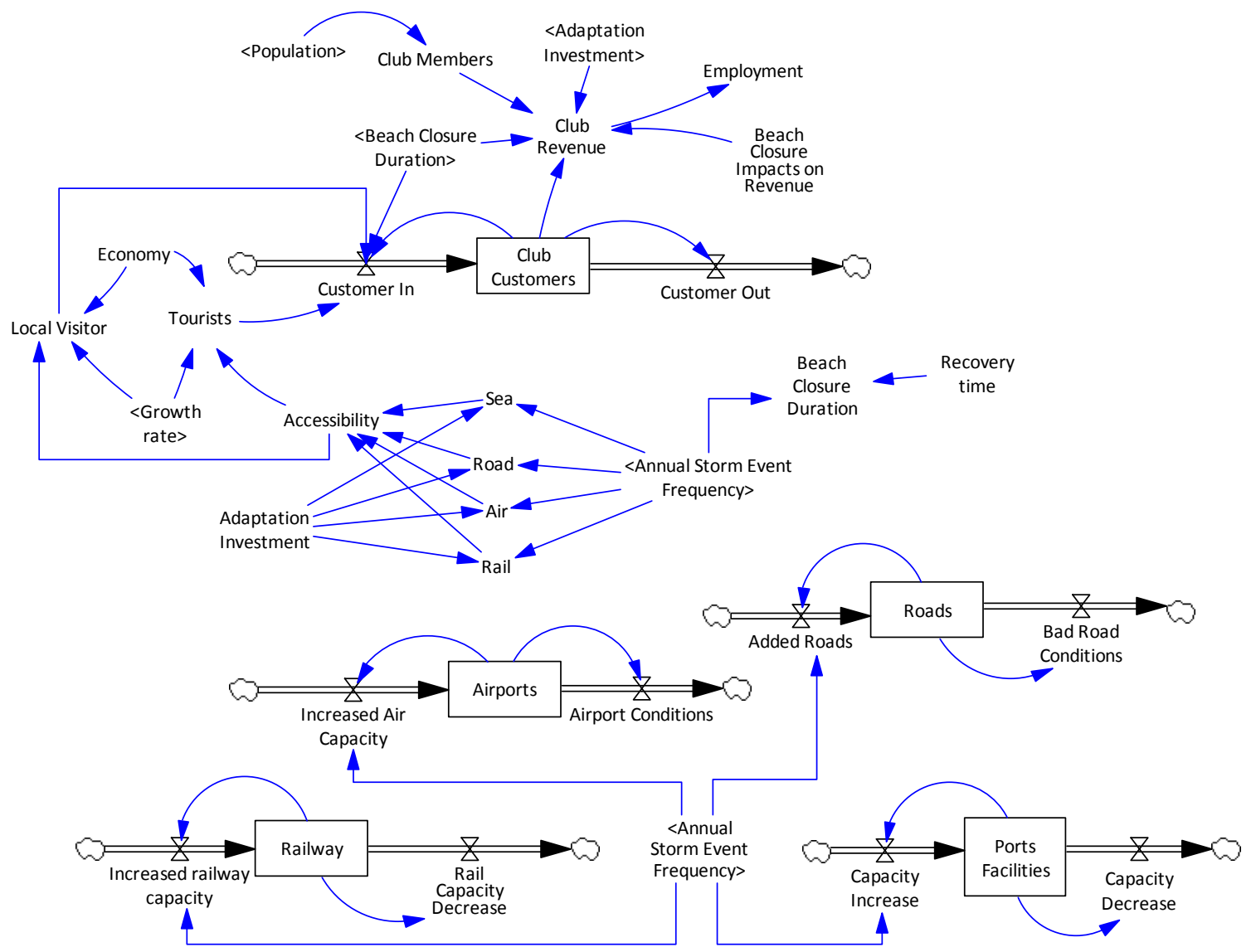

Figure 2. Operation sub-model showing the causal relationships between variables

Accessibility was identified during the workshops as a key factor affecting a SLSC's operation. Higher (or easier) accessibility would result in more customers (e.g. diners) and, consequently, more revenue. An increase in $A S E F$ is linked to beach and road closures and therefore would likely reduce patronage of a SLSC. Therefore, adaptation investment on all forms of accessibility would reduce the impact of extreme storm events on the clubs' operation. The variable, Club Customers relies on Accessibility, Local Visitors, Tourists and Beach Closure Duration, and was computed using the following equations:

Club Customers $=\int($ Customer In-Customer Out $) \mathrm{dt}+[100]$

Customer In $=($ Local Visitor + Tourists $) *$ Club Customers $*(1-$ Beach Closure Duration/365)

Customer Out $=$ Club Customers

Beach Closure Duration $=$ Annual Storm Event Frequency $*$ Recovery time

The Customer In (initial level = 100) variable represents the average number of customers visiting a SLSC. It is modelled as a function of Local Visitors, Tourists and Beach Closure Duration. Beach Closure is a function of $A S E F$ with beaches being closed during the storm events and subsequently reopened after a few days depending on the recovery rate. The number of days beach remain closed over a year is calculated based on storm events and average duration of beach closure. 
Another key variable, Club Revenue, is a function of Club Customers and Beach Closure Duration. It is assumed in the model that the club revenue consists of $10 \%$ membership fee and $90 \%$ customers spending at the clubs. It is also assumed that, during each beach closure, the number of customers will be reduced by $20 \%$. It is also assumed that, investment in adaptation would reduce the negative impact by $50 \%$ by increasing the accessibility to the clubs during the extreme events. It is important to note that these default settings provide a starting point and that these variables can be controlled with a slider so that various impacts of reduction scenarios can be tested.

\subsection{Community Sub-model}

The community sub-model (Figure 3) is used to explore the impacts of changing climate, specifically extreme events, on community located around the SLSCs An increase in the local population would create more potential to improve a club's operations. The number of volunteers, beach goers, memberships and club visitors/customers are directly influenced by the number of people residing near within the 'catchment' of the SLSC. However, the population growth depends on the economic environment and quality of life. Increasing extreme events, according to information elicited from the stakeholders, may affect the population growth and economic growth negatively.

\section{CONCLUSIONS}

Dynamical concepts such as accumulation, feedback, and resilience, and the collaborative use of influence diagrams, causal-loop diagrams, and system archetypes to map out possible feedback structures, are essential elements of a practical systems approach (Newell et al., 2011). The use of a dynamic modelling framework requires numeric information about the

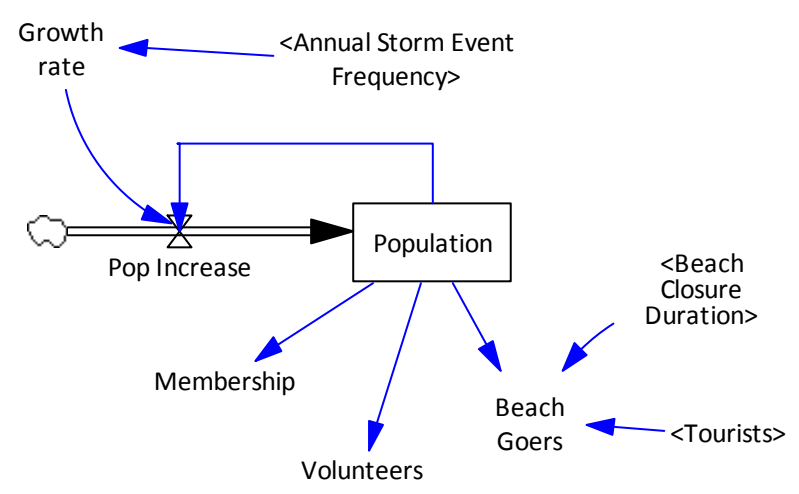

Figure 3. Community sub-model showing the relationships between variables. relationships between the system variables in order to describe them as formulas. However, as the available information about these relationships is partly or wholly too qualitative to be expressed trustworthily by a mathematical formula, it is difficult to develop a model explaining the system adequately. The structural analysis using MICMAC is capable of generating the required information about interrelationships between the key variables in a system by stakeholders. Thus, combination and utilizations of an array of techniques provided the potential for obtaining leverage in our systemic interventions. For example the SDM was used to: find the dominant feedback processes; perform sensitivity analysis in order to identify the leverage points: help in the finding of alternative strategies, which would lead to the action plan; to test and refine alternative strategies, while the MICMAC method used in the conceptualization stage to identify causal feedback loops between drivers affecting SLSCs.

\section{REFERENCES}

Arcade, J., Godet, M., Meunier, F. \& Roubelat, F. 1999. Structural analysis with the MICMAC method \& Actor's strategy with MACTOR method. Futures Research Methodology, American Council for the United Nations University: The Millennium Project, 1--69.

Berkhout, F., Hertin, J. \& Gann, D. M. 2006. Learning to adapt: organisational adaptation to climate change impacts. Climatic Change, 78, 135-156.

Dietz, T. 2003. What is a good decision? Criteria for Environmental Decision Making. Human Ecology Review, 10, 60-67.

Elrick, C., Dalton, L. \& Dalton, L. 2011. Impact of Extreme Weather Events and Climate Change on Surf Life Saving Services: A Road Map for Adaptive Action, report prepared for Surf Life Saving Australia.

Godet, M. 2006. Creating futures : scenario planning as a strategic management tool, London, Economica.

Harper, B., Granger, K., Jones, T., Stehle, J. \& Lacey, R. 2000. Tropical Cyclone Risks In: Granger, K. \& Hayne, M. (eds.) Natural hazards and the risks they pose to South-East Queensland. Canberra, Australia: Australian Geological Survey Organisation and Bureau of Meteorology. 
Huntjens, P., Lebel, L., Pahl-Wostl, C., Camkin, J., Schulze, R. \& Kranz, N. 2012. Institutional design propositions for the governance of adaptation to climate change in the water sector. Global Environmental Change, 22, 67-81.

Johnson, M. 2009. Public Participation and Perceptions of Watershed Modeling. Society \& Natural Resources, 22, 79-87.

Kauffman, S. 1993. The Origins of Order: Self-Organization and Selection in Evolution, Oxford University Press, USA.

Korfmacher, K. S. 2001. The politics of participation in watershed modeling. Environmental Management, 27, 161-176.

Langsdale, S., Beall, A., Carmichael, J., Cohen, S. \& Forster, C. 2007. Stacy Langsdale, Allyson Beall, Jeff Carmichael, Stewart Cohen, Craig Forster. Integrated Assessment Journal, 7, 51-79.

Newell, B., Marsh, D. M. \& Sharma, D. 2011. Enhancing the Resilience of the Australian National Electricity Market: Taking a Systems Approach in Policy Development. Ecology and Society, 16.

Patten, B. C. \& Jørgensen, S. E. 1995. Complex Ecology: The Part-Whole Relation in Ecosystems, Englewood Cliffs, New Jersey, Prentice Hall.

PWC 2011. What is the economic contribution of Surf Life Saving in Australia? .

Rosenzweig, C., Solecki, W., Blake, R., Bowman, M., Faris, C., Gornitz, V., Horton, R., Jacob, K., LeBlanc, A., Leichenko, R., Linkin, M., Major, D., O’Grady, M., Patrick, L., Sussman, E., Yohe, G. \& Zimmerman, R. 2011. Developing coastal adaptation to climate change in the New York City infrastructure-shed: process, approach, tools, and strategies. Climatic Change, 106, 93-127.

Sahin, O., Mohamed, S., Warnken, J. \& Rahman, A. 2013a. Assessment of Sea Level Rise Adaptation Options: Multiple-Criteria Decision-Making Approach Involving Stakeholders. Structural Survey, 31(4), 283-300.

Sahin, O., Mohamed, S., 2013. A spatial temporal decision framework for adaptation to sea level rise. Environmental Modelling \& Software, In Press.

Sahin, O., Stewart, R. A. \& Helfer, F. 2013b. Bridging the Water Supply-Demand Gap in Australia: A Desalination Case Study. European Water Resources Association (EWRA) 8th International Conference. Porto, Portugal: European Water Resources Association.

Sano, M., Gonzalez-Riancho, P., Areizaga, J. \& Medina, R. 2010. The Strategy for Coastal Sustainability: A Spanish Initiative for ICZM. Coastal Management, 38, 76-96.

Sanò, M., Richards, R., Sahin, O., Ware, D., Sherker, S. \& Tomlinson, R. 2013. Adapt between the flags: enhancing the capacity of Surf Life Saving Australia to cope with climate change and to leverage adaptation within coastal communities. Gold Coast: National Climate Change Adaptation Research Facility,.

Siems, R., Sahin, O., Talebpour, R., Stewart, R. \& Hopewell, M. 2013. Energy intensity of decentralised water supply systems utilised in addressing water shortages. European Water Resources Association 8th International Conference Porto, Portugal: European Water Resources Association.

Sojda, R. 2007. Empirical evaluation of decision support systems: Needs, definitions, potential methods, and an example pertaining to waterfowl management. Environmental Modelling \& Software, 22, 269277.

Tobey, J., Rubinoff, P., Robadue, D., Ricci, G., Volk, R., Furlow, J. \& Anderson, G. 2010. Practicing Coastal Adaptation to Climate Change: Lessons from Integrated Coastal Management. Coastal Management, 38, 317-335.

Van den Belt, M., Dietz, T., van den Belt, M. \& ebrary Inc. 2004. Mediated modeling : a system dynamics approach to environmental consensus building, Washington, DC, Island press.

Vennix, J. A. M., Akkermans, H. A. \& Rouwette, E. A. J. A. 1996. Group model-building to facilitate organizational change: An exploratory study. System Dynamics Review, 12, 39-58.

Ventana Systems 2012. Vensim DSS. 6.0b ed. Harvard, MA: Ventana Systems, Inc.

Voinov, A. \& Gaddis, E. J. B. 2008. Lessons for successful participatory watershed modeling: A perspective from modeling practitioners. Ecological Modelling, 216, 197-207.

Winn, M., Kirchgeorg, M., Griffiths, A., Linnenluecke, M. K. \& Günther, E. 2011. Impacts from climate change on organizations: a conceptual foundation. Business Strategy and the Environment, 20, $157-$ 173.

Young, O. R. 2010. Institutional dynamics: Resilience, vulnerability and adaptation in environmental and resource regimes. Global Environmental Change, 20, 378-385. 